\title{
Keeping an Eye on MRS's Long-Range Goals
}

I had planned to write about the state of the Materials Research Society (MRS) as I take office as its President, but somehow that seems a little inadequate now. Despite all the millennial ponderings of the year 2000 (my own included), and the fact that it is now already 2002, I think the 21 st century may really have begun on September 11, 2001, at least insofar as we like to associate changes of mindset with eras defined by the calendar. Some of us, who came of age before the 1990s, know that economic cycles come and go, but the present "downturn," accompanied and accelerated by many other world events, somehow has a very different look and feel than all the others that I rememberincluding the one that sent me into graduate school, for lack of decent job offers, in mid-1970s England. So instead of a narrow look at the state of MRS, or materials research as a whole, I would like to cast my comments in a slightly broader context, as I consider the role of MRS and materials research in the world of today.

About a year and a half ago, a group of MRS leaders began a strategic planning exercise and one of its outcomes was a mission statement, which is presented on this page. I know only too well the disdain that many of you have for strategic plans, mission statements, and for planning in general: We all know what we do and how we do it, after all, but it is also important to remember why we do it. The mission statement is clear on this point: MRS promotes the advancement of materials research "to improve the quality of life." Certainly, we argued about such a broad and vague statement-whether it even added anything of substance to the mission statement-but eventually it was the one version with which everyone could agree. And now, in this new world, it is essential to affirm that research does indeed have a purpose. Elegant theories

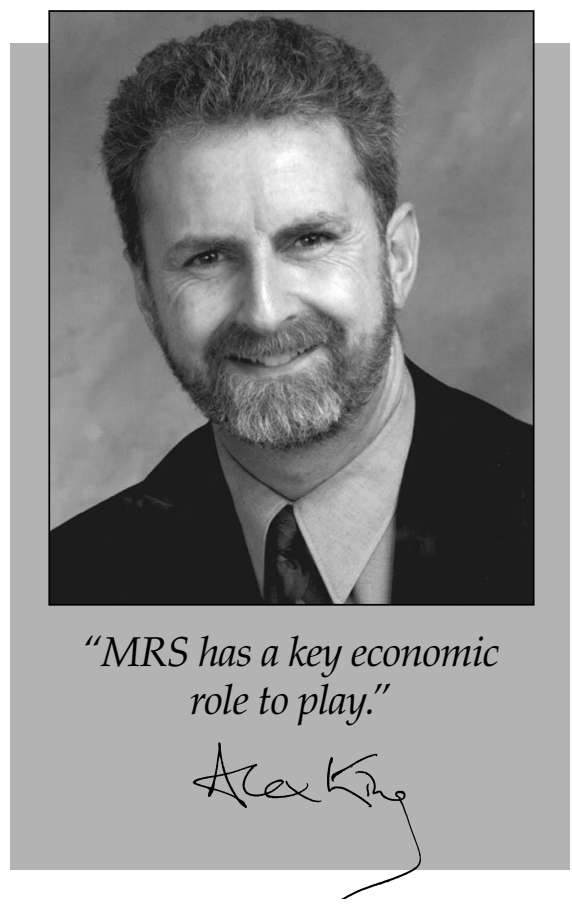

and clever explanations of obscure phenomena have their place, perhaps more akin to art than engineering in the manner in which they improve the quality of life, but the real reason why researchers spend their companies' money or the taxpayers' money is to have an impact on the quality of life for the whole of society, not just for those few who have the training to appreciate an elegantly devised theory or experiment. They have this impact in many direct and indirect ways: by creating technologies and products that improve or extend life, and by sustaining the economy so that more people are able to enjoy the benefits of our success. So I am challenging MRS members to ask themselves at the end of each day, not whether they made progress toward their next publication in the Journal of Materials

\section{MRS Mission Statement}

The Materials Research Society (MRS) is an organization of materials researchers from academia, industry, and government that promotes communication for the advancement of interdisciplinary materials research to improve the quality of life.

Research, but whether they did something that will improve life for someone, somewhere, somehow? Results are not immediate, of course, but the purpose of a strategic plan is to keep the long-range goals in mind, and that is what I am challenging you to do.

Paradoxically, economic downturns provide the greatest opportunity for new technologies to emerge. New materials are the forerunners of new technologies, and new technologies are the drivers of much of the world's economy, so MRS and its members have a key economic role to play at this time. My second challenge to you as a researcher is to take the idea you have been developing in spare moments and write it up as a patent disclosure. Adopt a New Year's resolution, along with me, to be just a little less academic and a little more entrepreneurial this year.

The most direct and appropriate response to poor economic conditions and an uncertain security environment is simply to focus more clearly on what we do, and raise the level at which we do it. MRS will be sharply focused on its core mission of promoting communication about materials research as we weather the challenges to the Society brought on by a relatively low turnout at the 2001 Fall Meeting - a direct result of the 2001 recession and the September 11 terrorist attacks. We will not shy away from developing new programs and projects that promote this mission, and we will also work on developing strategic alliances that enhance it, but this is not a time in which to broaden our mission. The strategic plan for the Society is an unfinished document-and probably always will be- but it tells us what we do, why we do it, and what the priorities are for this year. I will address some of those in future months, but for now, remember to keep your eyes on the long-range goal of your work, and I will try to keep the Society's eyes on its own long-range goal: ultimately, to improve the quality of life.

Alex KING 2002 MRS President

\section{MRS Membership Directory}

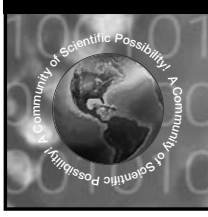

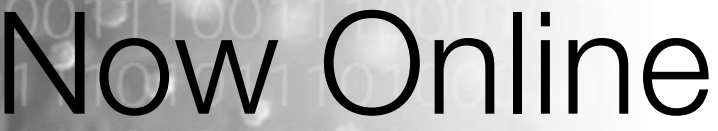

www.mrs.org/members/directory
Flexible_search by name, institution, and geographical location

Current-regularly updated

Convenient-linked to the MRS activities and contacts that will help you make the most of your MRS member benefits and services

Exclusive_professional networking service FREE to current MRS members only 